Faculdade de Ciências Econômicas UFRGS
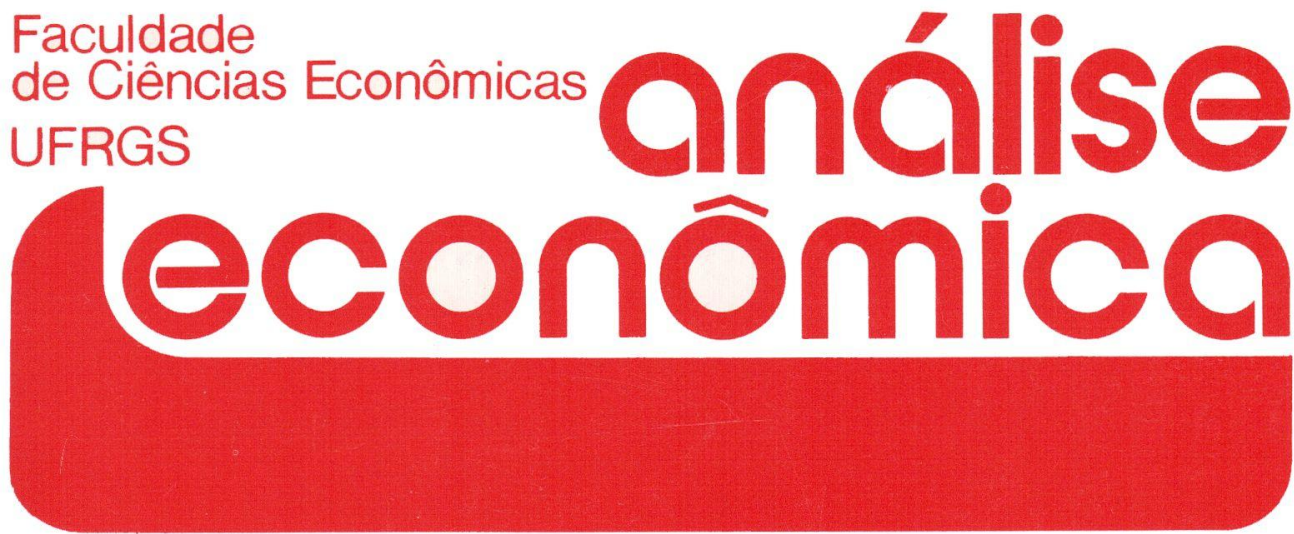

- STATE AND THE LIBERALIZATION OF THE BRAZILIAN ECONOMY

Carlos Alberto Longo

- MOEDA E CRÉDITO NA ECONOMIA BRASILEIRA: UM MODELO COM VETORES DE CORREÇÃO DE ERROS

Rolando M. Guzmán

- baSES PARA UM NOVO MOdELO DE POLítica FISCAL, PARA O BRASIL

Flávio Riani

- POR QUE OS SINOS DOBRAM? CONFLITO TRABALHISTA E SALÁRIOS DO MAGISTÉRIO PÚBLICO DO RIO GRANDE DO SUL, 1974-1991

Carlos Henrique Horn

Roberto Balau Calazans

- A POLÍtica MONETÁRIa E AS TAXAS de JUROS NO PLANO COLLOR

Lauro Lobo Burle

- DIFUSÃo E TRANSFERÊNCIA DA TECNOLOGIA DE PRODUÇÃO DE CIMENTO NO BRASIL

Maria Cristina Pereira de Melo

- SISTEMA FINANCEIRO BRASILEIRO: UMA PROPOSTA dE disCuSSÃo

Luiz Felipe Serpa

- TEORIA ECONÓMICA DO CASAMENTO E DO Divórcio

Giácomo Balbinotto Neto

- RESENHA

VARGAS: O CAPITALISMO EM CONSTRUÇÃO, DE PEDRO C. D. FONSECA

João Rogério Sanson

- LIVROS RECEBIDOS

Claudine Saldanha César
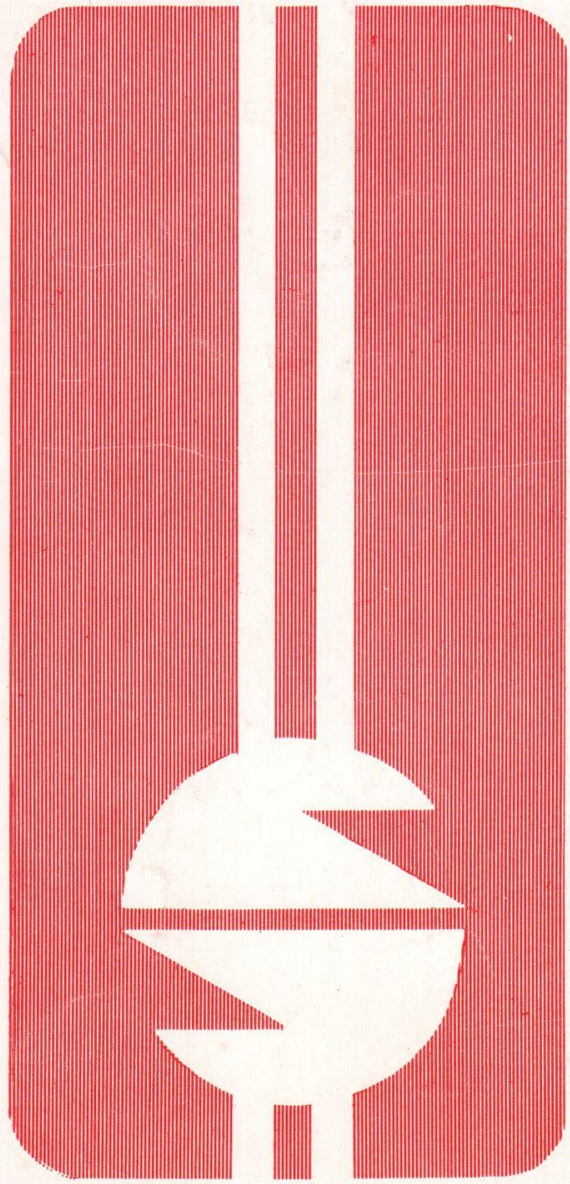
UNIVERSIDADE FEDERAL DO RIO GRANDE DO SUL

Reitor: Prof. Hélgio Henrique Casses Trindade

FACULDADE DE CIÉNCIAS ECONÔMICAS

Diretora: Prof ${ }^{a}$ Yeda Rorato Crusius

CENTRO DE ESTUDOS E PESQUISAS ECONÔMICAS

Diretor: Reinaldo Ignacio Adams

DEPARTAMENTO DE CIENNCIAS ECONÔMICAS

Chefe: Prof. Fernando Ferrari Filho

CURSO DE PÓS-GRADUAÇÃO EM ECONOMIA

Coordenador: Prof. João Rogério Sanson

CURSO DE PÓS-GRADUAÇÃO EM ECONOMIA RURAL

Coordenador: Prof. Juvir Luiz Mattuella

CONSELHO EDITORIAL: Achyles Barcelos da Costa, Aray Miguel Feldens, Atos Freitas Grawunder, Carlos Augusto Crusius, ErnaniHickmann, Fernando Ferrari Filho, João Rogério Sanson, Juvir Luiz Mattuella, Maria Imilda da Costa e Silva, Nali de Jesus de Souza, Nuno Renan Lopes de Figueiredo Pinto, Otília Beatriz Kroeĩ Carrion, Otto Guilherme Konzen, Paulo Alexaridre Spohr, Pedro Cezar Dutra Fonseca, Reinaldo Ignacio Adams, RobertsCamps Moraes, Valter José Stülp, Yeda Rorato Crusius, David Garlow (Wharton Econometrics Forecasts Association, E.U.A.), Edgar Augusto Lanzer (UFSC), Eleutério F. S. Prado (USP), Fernando Holanda Barbosa (FGV/RJ), Gustavo Franco (PUC/RJ), Joaquim Pinto de Andrade (UiNB), Juan H. Moldau (USP), Werner Baer (Univ. de Illinois, E.U.A.)

COMISSÃO EDITORIAL: Atos Freitas Grawunder, Reinaldo Ignacio Adams, Pedro Cezar Dutra Fonseca, Roberto Camps Moraes.

EDITOR: Nali Jesus de Souza

SECRETARIA: Maria Ivone de Mello (normalização), Vanete Ricacheski (revisão de textos)

FUNDADOR: Prof. Antônio Carlos Santos Rosa

Os materiais publicados na Revista Análise Econômica são de exclusiva responsabilidade dos autores. É permitida a reprodução total ou parcial dos trabalhos, desde que seja citada a fonte.

Aceita-se permuta com revistas congêneres. Aceitam-se, também, livros para divulgação, elaboração de resenhas ou recensões.

Toda correspondência, material para publicação (vide normas na $3^{a}$ capa), assinaturas e permutas devem ser dirigidos ao seguinte destinatário:

PROF. NALI DE JESUS DE SOUZA

Revista Análise Econômica

Av. João Pessoa, 52

90040-000 - PORTO ALEGRE (RS), BRASIL

Telefones: (051) 228.1633 - 224.6022 - Ramais 3348 ou 3440

FAX: (051) 225.1067 


\title{
DIFUSÃO E TRANSFERÊNCIA DA TECNOLOGIA DE PRODUÇÃO DE CIMENTO NO BRASIL
}

\section{Maria Cristina Pereira de Melo*}

\section{SINOPSE}

\begin{abstract}
Este artigo analisa o processo de difusão e transferência internacional da tecnologia de prodū āu de cimento no Brasil. Ele examina a evolução da produção de cimento em termos dos padröes mundiais, enfatizando o princípio da mudança tecnologica $A$ velocidade da introdução de novos processos de produção no País foi analisada. $O$ artigo estuda, também, a indústria de bens de capital para o setor de cimento no Brasil, procurando identificar o nível de apropriaçāo tecnológica.
\end{abstract}

\section{INTRODUÇÃO}

O objetivo deste artigo é o de analisar o processo de difusão e de transferência da tecnologia de produção de cimento no Brasil. Nossa abordagem consistirá em apresentar, primeiramente, um breve histórico da evolução da base técnica de produção de cimento, a fim de estabelecer uma periodização, observando as principais mudanças tecnológicas que ocorreram em nível mundial.

Em seguida, passaremos à análise da forma e ritmo de introdução dos novos processos de produção de cinınto no caso brasileiro, ou seja, o processo de difusãu tecnológica na indústria em questão.

Por fim, analisaremos a problemática da transferência de tecnologia observando, em particular, o setor produtor de bens de equipamentos destinados à indústria cimenteira.

* Professora do Curso de Mestrado em Economia - CAEN/CFC.

\begin{tabular}{|l|l|l|l|l|}
\hline ANÁLISE ECONÔMICA & ANO 10 & $\mathrm{~N}: 18$ & SETEMBRO/92 & P.95-112 \\
\hline
\end{tabular}




\section{NORMAS MUNDIAIS DE PRODUÇÃO: BREVE HISTÓRICO}

Nesta seção iremos nos dedicar ao exame dos traços relativos às normas mundiais de produção de cimento e, na seguinte, à difusão dessas normas no caso do Brasil. Trataremos as normas de produção como sendo a configuração técnicomaterial e de economia de tempo que prevalecem num espaço determinado, a um dado momento, no processo de produção cimenteiro. Tendo em conta a heterogeneidade da tecnologia nos diversos estabelecimentos industriais, não se pode estabelecer uma periodização precisa. Pode-se, apesar de tudo, indicar os momentos em que ocorrem avanços tecnológicos significativos.

A importância de apresentar a evolução das normas mundiais de produção deve-se ao fato de que esta evolução permite acompanhar a forma e o momento em que as novas técnicas de produção foram difundidas na indústria cimenteira brasileira.

O cimento portland foi patenteado em 1824. Segundo seu inventor Joseph Aspdin, o cimento é fabricado desde 1811 , contudo ele só foi difundido nos . nos 40 do mesmo século (Prochnik, 1983, p11).

O processo de produção de cimento portland consiste em três etapas fundamentais: a pedreira, a transformaçāo do produto e o ensacamento. $O$ produto elaborado pela indústria cimenteira é obtido pela transformação físico-química de dois elementos : argila e calcário. Estes elementos, depois de serem extraídos de suas pedreiras, são submetidos à britagem e encaminhados à primeira mistura. Em seguida, as matérias são moídas, homogeneizadas e calcinadas no forno onde então a mistura é transformada em clínquer. O clínquer será moído e alguns elementos - como o gesso - the são adicionados; cle será estocado, enquanto aguarda a expedição.

De maneira geral, o desenvolvimento tecnológico na indústria Cimenteira caracteriza-se pela pesquisa de dois aspectos complementares entre si: a) a procura sistemática da redução do consumo de energia e do custo de mão-de-obra e b) a procura de uma maior regularidade do fluxc de produção. O primeirc aspecto está associado à estrutura de preços inerente a esta indústria e à necessidade de busca do alargamento da margem de lucro pela via de diminuição do preço de venda do cimento. $\mathrm{O}$ segundo aspecto visa reduzir os tempos mortos entre as diferentes etapas da produção e, consequientemente, alcançar uma menor dependência da intervenção humana no desenvolvimento da produção(Coriat, 1980, p.51). ${ }^{1}$

É verdade que as mudanças tecnológicas não ocorrem da mesma maneira, nem no mesmo nível, em todos os setores da produção. A fim de facilitar a exposição apresentaremos dois grandes setores da produção de cimento: a) a pedreira e o ensacamento e b) a transformação. Ainda que o segundo constitua o setor estratégico do proc:sso produtivo, ele não é, no entanto, auto-suficiente.

1 Sobre os principais componentes e a estrutura de custos do cimento ver Angelier (1978, p.16-20). 
A pedreira e o ensacamento não eram mecanizados até a década de 30 deste século. Entre os anos de 1930e 1950 ocorreu uma fraca mecanização. Nos últimos trinta anos estes setores passaram por uma mecanização clássica potente e, em seguida, por uma mecanização semi-automática. Os efetivos médios da pedreira caíram, em três décadas, de 100 para ó pessoas e no ensacamento a empilhadeira suprimiu os postos de arrumadores. A modificação na pedreira "é marcada pela substituição dos martelos/perfuradores por sondadoras; de vagões por caminhões que desaparecem com a introdução, de um lado, do britador móvel no pé do fundo do corte e, de outro lado, pela esteira rolante; de pás manuais por pás mecânicas que deixam olugar para as carre $\bar{g}$ adeiras"(Dadoy, 1978, p.151-152). ${ }^{2}$ De seu lado, "no atelier de embalagem/expedição, os ensacadores mecânicos foram substituídos pelos automáticos; embora a colocação dos sacos nos bicos da ensacadeira seja ainda assegurada manualmente. A expedição, anteriormente assegurada pelos arrumadores que transportavam os sacos aié os trens, os caminhões e os barcos é hoje realizada, de um lado, por uma empilhadeira automática, onde as pás são carregadas nos caminhões por condutores, e, de outro lado, pelo carregamento feito a granel em livre serviço" (Dadoy, 1978, p.151-152).

Quanto ao setor estratégico, ou seja, a transformação propriamente dita, apresentaremos, primeiramente, a evolução que ocorreu nà base técnica do núcleo central da produção, o forno, a parte mais sensível do processo de produção, a fim de captar os pormenores dos diversos processos de produção.

Inicialmente, eram utilizados fornos verticais para se obter o clínquer. Estes fornos foram "desenvolvidos a partir da experiência acumulada na fabricação de cal e ladrilhos - nos quais se obtinha um conglomerado sinterizado a partir de grãos ou de outras estruturas pré-formadas. A introduçāo do forno rotativo, no fim do século passado, marcou um ponto de inflexão na técnica de cozimento do cimento"(Guimarães \& Reis, 1976, p. 162). Neste tipo de forno, "a mistura de calcário e argila, convenientemente preparada, é introduzida pela extremidade mais elevada do forno ligeiramente inclinado e, ao avançar de modo contínuo ao longo do mesmo, é sucessivamente seca , calcinada e sinterizada abandonandoo como clínquer em sua exïemidade inferior"(Guimarães \& Reis, 1976, p. 162 166). ${ }^{3}$

Os fornos rotativos são classificados segundo a mistura que os alimenta. Nos fornos via úmida, adiciona-se água para facilitar a homogeneização das matérias, o controle das operações é muito mais simples que nos fornos via seca. Durante algum tempo a utilização dos f́rnos via seca apresentava como problema principal a alta temperatura dos gazes que saíam dos fornos e que produziam grande quantidade de poeira com relação ao forno via úmida . Contudo o aspecto

2 A respeito da evolução tecnológica ver também L.utrin (1978, p. 9-13).

3 Sobre as mudanças tecnológicas ocorridas no processo de cozimento seguiremos o desenvolvimento apresentado pelo autor citado nas páginas 162-166. 
energético - quantidade de combustível requerido para queimar a mistura era significativamente menor - deu o impulso à procura de adaptações neste tipo de forno a fim de torná-lo competitivo face ao forno via úmida(Guimarães \& Reis, 1976, p. 162-163).

A primeira adaptação que teve sucesso foi a introdução do pré-aquecedor com grelha o qual fazia subir a temperatura da mistura crua antes de entrar no forno e permitia a utilização de baixas temperaturas dos gazes residuais. Este processo de pré-aquecimento ou processo de Lepol foi patenteado pela firma Polysius (alemã) e posto em operação pela primeira vez em 1929. Em 1952, este processo foi submetido a algumas modificações a fim de melhorar sua eficiência. Entretanto, o grande problema continuava sendo colocado: o material tomava a forma, antes de entrar no forno, que guardava até a saída(Guimarães \& Reis, 1976,p. 164).

Nos anos 50 , o processo via seca com pré-aquecimento a suspensão foi posto em operação pela primeira vez. Ele foi desenvolvido pela firma alemã KlocknerHumboldt-Deutz; desta vez a mistura crua ( sem adição de água e sem granulação prévia) era colocada em contato com os gazes do forno. $O$ sistema consiste em vários ciclones dispostos em série por onde a mistura crua passa, podendo chegar ao forno, já aquecida. Esses equipamentos tiveram " utilização crescente, uma vez que dispensavam a preparação prévia dos grãos requeñữa pelo processo Lepol, difícil no caso de determinados crus. Posteriormente, evoluiu-se do emprego desses pré-aquecedores como estrutura adicional aos velhos fornos para a utilização desses equipamentos como componente bem definido do processo de cozimento"(Guimarães \& Reis, 1976, p.165).

No processo de cozimento a introdução de pré-calcinadores destaca-se dentre as recentes inovações. A mistura crua e calcinada antes de entrar no forno. Esta inovação "permite acréscimo de $40 \%$ na produção do forno. sem implicar aumento de suas dimensões e sem elevar o consumo de combustível"(Guimarães \& Reis, 1976, p. 193). Esta inovação está associada à procura de uma maior escala de produção na medida em que a escala de produção máxima nos fornos via-seca é de 6000 toneladas/dia com pré-aquecedor de quatro estágios de ciclones enquantr que o forno via isca (com pré-aquecedor e pré-calcinador) a produção pede alcançar um máximo de 12000 toneladas/dia, tomando por base fornos nos limites tecnológicos máximo de diâmetro aceitável - seja 7 metros (Lutrin, 1978, p.48). Em 1976, empresas como a Polysius (alemã),F.L.Smith (dinamarquesa) e Humboldt (alemã) produziam os equipamentos requeridos para a pré-calcinação. Nesta época, 45 usinas de cimento - correspondendo a $8 \%$ da produção mundial - utilizavam o novo sistema no processo de fabricação. Sem dúvida, as usinas de maior capacidade produtiva estão localizadas no Japão, istoé, as usinas com fornos possuindo capacidade superior a 5000 toneladas/dia (Guimarães Reis, 1976, p. $164) .^{4}$

4 Ver também Lafarge Consultoria e Estudos (1982, p.51) 
Esta evolução tecnológica que teve lugar no processo de cozimento não dá conta de todas as modificações que se pode identificar no setor de transformação. Apresentaremos a seguir os traços gerais do seu conjunto.

A evolução tecnológica no conjunto do setor de transformação, dos anos 50 até hoje, caracteriza-se "pela passagem de uma instalação constituída de numerosos aparelhos individualizados com condução manual, exigindo do operador a elaboração de decisões a partir de índices captados pelos sentidos e de numerosas intervenções diretas sobre as máquinas, para uma utilização complexa e sofisticada, dentro da qual os aparelhos estão integrados, a condução automática gerida por computadores, e todos os elementos de informação sobre as características do produto em curso de transformação são reunidas na sala central' (Dadoy, 1978, p. 151).

De um lado, a centralização faz economia de custo de mão-de-obra, de outro lado ela procura fundamentalmente melhor rentabilidade, melhor regularidade do produto, melhor qualidade e mais eficiente proteção do material (Lutrin, 1978, p. 13)..$^{5}$

\section{DIFUSÃO DAS NORMAS MUNDIAIS DE PRODUÇÃO NA INDÚSTRIA BRASILEIRA}

Para analisar de que maneira a difusão tecnológica ocorre no interior do aparelho produtivo brasileiroe, em particular, na indústria cimenteira, tomaremos como ponto de partida os anos 30 , quando a economia brasileira direciona-se para uma estrutura produtiva de base urbano-industrial.

Tendo em conta a não-disponibilidade de tecnologia em nível interno do país, os capitais que se lançaram na atividade industrial de fabricação de cimento tiveram como alternativa o mercado externo para adquirir a tecnologia necessária para transformar as matérias primas.

Os principais fornecedores de tecnologia para a indústria cimenteira são as firmas.F.L.Smidth (dinamarquesa), Polysius/Krup (alemã) e Allis Chalmers (americana). Eles concentram não somente a etapa de elaboração do projeto detalhado mas também controlam, direta ou indiretamente, a fabricação de equipamentos, o que assegura suas posições no mercado mundial. A importância dessas firmas para o desenvolvimento tecnológico no ramo cimenteiro já foi assinalada acima. Os fluxos tecnológicos são diversos e, muitas vezes, duráveis quando se trata da aquisição da tecnologia de uso do processo de cimento. Estes fluxos são efetuados pelas firmas através das atividades:

a) de investigação da mina das matérias-primas;

b) de pesquisa e de ensaio a fim de elaborar o projeto;

c) de construção e de montagem da usina;

5 A respeito das vantagens técnicas da automatizaç ão na indústria cimenteira e a rentabilidade que dela decorre ver L afarge Consultoria e Estudos (1982, p.2-4). 
d) da formação do pessoal para implantação das instalações;

e) da completa assistência técnica(Guimarães \& Reis, 1976, p.192) .

E verdade que quando um fornecedor de tecnologia concede aos fabricantes de cimento a tecnologia de uso do processo, ele os habilita a utilizar as unidades industriais com eficiência.

Contudo o primeiro guarda certos segredos essenciais ao processo, levando a uma certa dependência do fabricante de cimento com relação ao fornecedor de equipamentos, o que engendra a necessidade de contratos duráveis de assistência técnica entre eles. ${ }^{6}$

A empresa F.L.Smidth, o maior produtor mundial de equipamentos para a indústria de cimento tornou-se, de longe, o maior fornecedor da indústria cimenteira brasileira. Em 1983, esta firma participava com $48,88 \%$ do total da capacidade instalada de produção de clínquer, seguida pela Polysius com 11,95\%. Esta predominância pode ser explicada segundo Guimarães \& Reis (1976, p. 216), "de ún lado a própria dinâmica da oferta internacional de tecnologia e a concentração das atividades dos fornecedores europeus em determinadas áreas do mercado mundial. De outro, os bons resultados obtidos com os fornos instalados anteriormente, a qualidade da assistência técnica prestada, as técnicas de marketing da empresa e a aversão ao risco dos fabricantes nacionais de cimento explicitada principalmente na importância conferida as garantias de performance do fornecedor do projeto e do equipamento".

De fato, a escolha do fornecedor de tecnologia é uma decisão individual de cada empresário o qual procura conjugar diversos aspectos: dos elementos técnicos aos custos financeiros. Pode-se observar a existência de uma conjugação de elementos a serem analisados pelo comprador, onde o peso difere, em graus diversos, de um empresário para outro no momento da escolha. É difícil estabelecer uma norma geral que oriente a decisão. É preciso assinalarque quando se trata de um investimento que deva ser realizado pelos grupos já em operação no ramo, o peso mais forte recai na relação já estabelecida com o fornecedor. No Brasil, uma vez que o fabricante de cimento estabeleceu ligações com um certo fornecedor de tecnologia, ele terá tendência, nos seus projetos futuros, de tomar essas relações cada vez mais estreitas.

Diante do que foi exposto, é possível compreender as origens da atual configuração da indústria cimenteira brasileira no que se refere aos fornos instalados por fornecedor e os grupos econômicos. O grupo Votorantim utiliza tecnologia fornecida pela F.L.Smidth, o grupo João Santos utiliza sobretudo fornos produzidos pela empresa checa Prerov Machinery o grupo Paraíso utiliza

6 A assistência técnica distingue-se dos serviços técnicos na medida em que ela pode ser definida como assistência ou consultoria permanente, remunerada como percentagem da produçąo ou por unidade de produçăo, enquanto os serviços técnicos têm um caráter temporário FGV (1983, p 68). 
também a tecnologia F.L.Smidth, isto para apenas citar os maiores grupos do setor. ${ }^{7}$

De um lado, o fornecedor, conhecedor profundo do produto a ser vendido, tem tendência a induzir tal ou tal escolha tecnológica. De outro lado, a escolha do fabricante de cimento depende, em certa medida, das condições locais de informação, avaliação e adaptação da tecnologia a ser adquirida. Conhece-se, contudo, a racionalidade do capital que procura a minimização dos custos de produção, permitindo sua reprodução de maneira satisfatória no espaço sócioeconômico onde está inserido. Depois de haver apresentado os aspectos referentes à relação fornecedor de tecnologia/fabricante de cimento, passaremos à problemática da difusão propriamente dita.

Para melhor compreender o processo de difusão das inovações tecnológicas na indústria cimenteira brasileira apresentaremos, em seguida, uma cronologia da introdução dos novos processos no país. É preciso assinalar que apenas será objeto as modificações referentes ao núcleo central da produção e na sua parte mais delicada - o forno. ${ }^{8}$

A primeira usina de cimento instalada no Brasil,em 1926, adotou o processo via seca com fornos longos expedidos pela Allis Chalmers - a usina Perus de capital canadense.

No decorrer dos primeiros 25 anos de atividade, o setor cimenteiro brasileiro adotou o processo via úmida que, na época, apresentava maior eficiência operacional. Com efeito, este processo era então o mais difundido mundialmente. 0 primeiro forno via úmida foi instalado em 1933 na usina Nacional/São Gonçalo pertencente ao grupo Lone Star (americano).

Conforme assinalamos, as modificações no processo via seca com a introdução da grelha ocorreu no início dos anos 1950. Na primeira metade dessa década, os dois primeiros fornos curtos com pré-aquecedor a grelha foram introduzidos no Brasil. Em 1953, o grupo Votorantim adota este tipo de forno expedidopor F. L. Smidth na sua usina de Esteio: em 1954, ogrupo Paraíso adotouo também na sua usina Ponte Alta recorrendo ao mesmo fornecedor. As causas da parada da difusão deste process $仓$, com气 já assinalamos, devem-se aos inconvenientes técnicos.

A introdução dos fornos via seca com pré-aquecedor a suspensão ocorreu em 1966, quando o grupo João Santos procedeu a expansão de sua usina de Itapessoca - tecnologia Humboldt - e que o grupo Votorantim fez a reconversão de um forno via úmida para via seca utilizando os equipamentos de seu tradicional fornecedor - F. L. Smidth. A partir deste momento outros grupos cimenteiros adotaram progressivamente este tipo de forno nas novas usinas e na expansão daquelas

7 Informạ̧ão obtida junto ao Sindicato Nacional da Indústria de Cimento.

8 Para estabelecer a cronologia seguimos Guimarães \& Reis (1976, p. 203-213) 
existentes. Desta maneira, a partir de 1972, todos os.fornos instalados no país foram via seca.

Por sua vez, os fornos com pré-aquecedor com quatro estágios de ciclones foram adotados pela primeira vez em 1970 pelo grupo Votorantim que os comprou da firma dinamarquesa. Os dois fornos instalados por este grupo cimenteiro brasileiro - é preciso assinalar - eram o segundo e o terceiro fornos do gênero construídos no mundo pela firma fornecedora.

A introdução dos fornos com pré-calcinador ocorreu em 1982 no momento da entrada em funcionamento da usina MAUA/Cantagalo pertencente ao consórcio Lafarge (francesa) e Lone Star(americana) - que utiliza equipamentos F. L. Smidth.

Diante do que foi exposto, podemos indicar alguns elementos que, em níveis diferentes, influenciaram a adoção de um novo processo.

A introdução do processo via úmida parece mais fácil de ser entendida já que na época em que foi introduzido no Brasil ele era o processo melhor considerado mundialmente. Diante deste fato, basearemos nossa análise no processo de difusão da linha via seca de fornos curtos com pré-aquecedor a suspensãô o qual constitui, sem dúvida, o primeiro grande salto tecnológico no processo de transformação para obter cimento.

De acordo com a cronologia apresentada, observa-se que o ultimo processo foi introduzido no Brasil na segunda metade da década de 60 e largamente difundido ao longo dos anos 70.

Os aspectos que determinam a adoção de uma nova tecnologia dependem, no nosso ponto de vista, de elementos que se entrelaçam relativos a constrangimentos internos e externos. Queremos apenas ressaltar dois elementos cruciais no momento da decisão da adoção do processo via seca. O primeiro aspecto, associado ao constrangimento externo, refere-se à estreita relação entre o fornecedor de tecnologia e o fabricante de cimento, de onde decorrem as opções tecnológicas coiucadas à disposição pelos primeiros. O segundo aspecto, isto é, o constrangimento interno, depende do custo de energia, crescente ao longo dos anos 60; entre 1963 e 1960 o preço real de óleo combustível aumentou $39 \% .^{9}$

A introdução do processo via seca no Brasil ocorreu no mesmo período que em outros países - tal a França - o adotou quando da modernização de sua indústria cimenteira. De fato, na França é apenas a partir da segunda metade da década de 60 que o processo via seca tornou-se predominante. Em 1965, 58\% da capacidade instalada dos fornos era ainda representada pela via úmida (Angelier, 1978, p. 19). Referindo-se às coincidências dos fatos e das datas entre a indústria cimenteira

9 Em 1962, a firma F.L.Smidth começou fabricar fornos com prế-aquecedor a suspensão. Sobre a evolução do preço do óleo combustivel Guimarães \& Reis (1976,tabela III 18). 
francesa e a brasileira Coriat (1981, p.28) ${ }^{10}$ diz que "é no mesmo período (fím dos anos 60 e início dos anos 70) que os grupos cimenteiros na França aceleraram a modernização de suas instalações".

Tomando-se como exemplo duas usinas pertencentes ao grupo Lafarge Matozinhos adquirida, em 1959, e Maua instalada em 1982 - observa-se que ambas acompanharam, pelo menos no que se refere ao processo de transformação, a "filiere" técnica de suas congêneres francesas. A primeira instalou em 1959 um forno via úmida " exatamente o mesmo modelo da usina de Boussens (perto de StGaudens nos Pirineus) que a serviu de referência ...Em 1972, a usina expandiu-se: uma nova linha de produção foi instalada, "via seca" ... (Coriat, 1981, p.25). A segunda usina, por sua vez, instalou em 1982 o processo via seca com précalcinador semelhante ao utilizado pela usina francesa de Haubourdin, segundo informações obtidas junto à empresa no Brasil.

\section{APROPRIAÇÃo DA TECNOLOGIA DE PROCESSO NO BRASIL}

Um exame da realidade tecnológica da indústria de bens de equipamento para o setor cimenteiro no Brasil passa pela compreensão do movimento de circulação internacional de tecnologia. Nisse sentido, faremos inicialmente breves considerações sobre o referido movimento em geral para, em seguida, nos determos no caso concreto específico ora proposto.

Para bem compreender o movimento de circulação internacional de tecnologia, é importante tecer algumas considerações sobre as condições de mercado nas quais ocorre a realização dos produtos tecnológicos. A difusão internacional de tecnologia, quer dizer a extensão da tecnologia de uso de um bem de produção, ocorre com o máximo interesse de seu produtor visto que a maior difusão de seu produto engendrará o alargamento de seu mercado. Quando se trata de transferência de tecnologia, um aspecto restritivo do mercado se impõe, o detentor tenta de toda maneira guardar o controle da exploração da tecnologia em questão."

De um lado, a difusão internacional de tecnologia ocorre, de certa maneira, sem obstáculo, num mercadio mundial constituído; de outro lado, a transferência de tecnologia está ligada a um mercado cada vez mais cativo, dominado sobretudo por firmas multinacionais.

10 Este argumento ć contestado por Guimarães \& Reis (1976, p 218), segundo os quais havia um atraso na

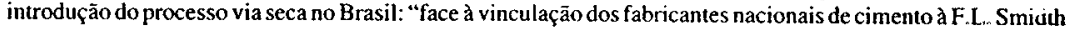
e a política dessa empresa no tocante aos fomos com pré-aquecedores por suspensão, parece lícito associar à circunstância desses vínculos a avaliação dos fabricantes nacionais relativa a tais fornos $\mathrm{e} o$ atraso de sua introdução no Brasil". Os autores assinalam ainda que não somente deve-se "tribuir o atraso a esta dependência do fornecedor mas "identificar, também, no plano interno, os fatores que respondem pela ausência de pressōes sobre fabricantes nacionais no sentido de inovar". Estas determinaçōes, segundo os autores "devem ser encontradas no contexto da estrutura e da dinâtnica do mercado e da indústria no período".

11 Sobre o movimento de circulação internacional de tecnologia ver: Madeuf (1981); Perrin (1983). 
É preciso interrogar-se sobre o que constitui efetivamente uma verdadeira operação de transferência de tecnologia. A propósito deste assunto existem dois pontos de vista diferentes. O primeiro, bastante aceito, considera como transferênciade tecnologia todos os fluxos internacionais portadores de conteúdo tecnológico, incluindo compra de bens de equipamento e usinas completas, acordo de assistência técnica, acordo de cooperação, programa de formação de pessoal, patentes, licenças, etc. $O$ segundo admite uma concepção muito mais restrita do termo: a transferência de tecnologia ocorre quando a transmissão de um saber - conhecimento tecnológico - permite o domínio progressivo da tecnologia. Neste sentido, o processo de aprendizagem da tecnologia conduz ao crescimento da capacidade de engenharia nacional. Compartilhamos inteiramente desta última concepção e aceitamos que a verdadeira transferência de tecnologia é aquela que torna possível o domínio progressivo da tecnologia, isto é, o recebedor adquire os meios de familiarizar-se com as técnicas, controlá-las, dominá-las, adaptá-las e criá-las. ${ }^{12}$

Para chegar ao domínio de determinada tecnologia, é preciso colocar em ação uma estratégia de engenharia nacional, isto é: é preciso ter como objetivo a estruturação progressiva e de maneira autônoma da capacidade de engenharia nacional.

É preciso não confundir a transmissão do sảer apresentada acima com aquela associada às regulagens e ao modo de condução das operações que levam ao domínio da condução do processo de produção concernente, visto que esta transmissão contém sobretudo know-how técnico e menos conhecimento tecnológico. De fato, o know-how técnicoé facilmente alienado. Ele é transmitido através de acordos de cooperação técnica, de assistência, dos programas de formação. Este tipo de transmissão consiste apenas em uma comunicação de informações. Trata-se de uma falsa operação de transferência de tecnologia.

Por seu lado, a transmissão do saber contendo conhecimentos tecnológicos passíveis de serem dominados é mais difícil de ser alienada. Este tipo de transmissão faz parte de um mercado cativo onde as firmas multinacionais jogam um papel dominante, tal qual assinalamos acima.

Até os anos 60, a importação de tecnologia pelos países latino-americanos era considerada, por seus governos, como um meio de acelerar os respectivos desenvolvimentos industriais. Por volta do final da década de 60 , novas preocupações apareceram devidas ao mercado de tecnologia, ao seu custo e as relações entre filiais e matrizes de firmas multinacionais. Vários trabalhos foram realizados por organismos regionais tais como: o Pacto Andino, a Conissão Econômica para a América Latina(CEPAL), a Organização dos Estados Americanos (OEA), os quais propuseram uma regulamentação sobre a transferência de tecnologia e o capital estrangeiro. Desta forma, foi estabelecido através do acordo de Cartagena o Regime comum de tratamento dos capitais estrangeiros e de marcas e patentes.

12 A propósito dessa concepção de transferência de tecnologia ver particularmente Judet \& Perrin (1977). 
O Brasil, país que já possuía um organismo de controle dos contratos de transferência de tecnologia - Instituto de Propriedade Industrial (INPI) - adotou o modelo de legislação proposto pelo Acordo a partir de então.

Em 1971,13 o Código de Propriedade Industrial foi elaborado e, em 1975, o INPI resolveu, através do ato normativo n" 15 de 11/09/1975, "estabelecer conceitos básicos e expedir normas, para fins de averbação de contratos de transferência de tecnologia e correlatos"(INPI, 1975, p.5).

No final dos anos 60 , restrições à importação de tecnologia, sobretudo incorporada aos bens de equipamentos, foram impostas. Compreende-se, pois, que as firmas multinacionais - que detinham a tecnologia de processo do cimento e que já possuíam escritório de representação no Brasil para servir de intermediário entre contratantes anteriores - tomaram consciência e resolveram instalar-se como indústrias mecânicas.

No Brasil as políticas específicas, a partir dos anos 70, relativas à importação de tecnologia desincorporada, ao fluxo de investimento externo e ao controle de importações de tecnologia incorporada aos bens de equipamento, se inserem dentro da estratégia geral de importação de tecnologia. A política econômica brasileira, desde os anos 50, foi favorável, sobretudo, ao investimento externo direto, procurando, assim, resolver os problemas de insuficiência tecnológica e/ ou financeira.

Para melhor compreender de que maneira ocorre a produção de equipamentos destinada à indústria cimenteira, apresentaremos as principais empresas segundo o produto e a origem do capital.

Primeiramente, é importante ressaltar que o ciclo produtivo do equipamento é constituído de três fases: a) projeto básico; b) projeto detalhado e c) execução de desenhos de fabricação. Se as duas primeiras etapas ccnstituem o segredo a ser guardado pelos detentores de tecnologia, a terceira pode ser subcontratada.

Num primeiro momento, no Brasil, todos os equipamentos necessários à fabricação de cimento eram impertados. Pouco a pouco alguns elementos foram subcontratados no interior do país, e, na década de 70, filiais das grandes fïmas multinacionais que detinham a tecnologia de processo do cimento instalaram-se. quais: 14

Dessa forma, atualmente, encontram-se instaladas no país empresas tais

- "Fábrica de Aço Paulista S.A."; filial da Allis Chalmers americana, produz os principais equipamentos é a mais tradicional fornecedora de moinhos para a indüstria cimenteira brasileira;

13 Esta data corresponde ao momento em que o INPI assume o papel de controlador efetivo da importaçāo de tecnologia que antes era exercido pelo Banco Central.

14 As informaçöes são cruzadas de pesquisa pessoal efetuada junto ao INPI; Associação Brasileira de Mercado de Capitais (1981, p.31-34); EMBRAME.C (1979, p.6-11). 
- "Krupp Indústria Mecânica Ltda"; instalada em 1973, filial da Krupp alemã, produz toda sorte de máquinas e equipamentos para a fabricação de cimento;

- "Mecânica Pesada S.A.”; inaugurada em 1957 pertence ao grupo Schneider \& Cia. é apenas a partir de 1971, quando se associa ao grupo francês Creusot Loire, que a empresa passa a produzir equipamentos para a fabricação de cimento;

- "Indústria Pesada F. L. Smidth \& Co A/S", produz toda sorte de equipamentos para a indústria cimenteira.

A diversidade dos equipamentos necessários à implantação de uma usina de cimento é tão grande quanto sua complexidade. Neste sentido, estas empresas concentram-se sobretudo na fabricação de peças-chave de seus produtos, subcontratando aquilo que está disponível no interior do país ou o que é passível de ser desenvolvido internamente. ${ }^{15}$

A subcontratação para a execução de projetos de peças ou mesmo de equipamentos ocorre de maneira dispersa. No nosso entender, isto faz parte da estratégia destas firmas a fim de controlar a tecnologia que elas detêm.

O número de empresas que opera no Brasil na fabricação de peças e acessórios destinados à indústria de cimento é de 46(ABAMEC, 1981). As quatro firmas apresentadas acima fazem parte do grupode filiais de firmas multinacionais que detêm a tecnologia de processo. Por outro lado, existem empresas de capital nacional capazes de executar de senhos de fabricação de moinhos, fornos, ciclones, etc., a partir de licença concedida por outra empresa. Um exemplo característico é a empresa Jaguará S/A Mecânica. Esta utiliza a tecnologia da empresa inglesa Newell Dunford Eng. Ltda., porém ela não é autônoma na concepção do projeto básico(EMBRAMEC, 1979, p.7).

De um lado, o desequilíbrio das contas externas do país impôs medidas cada vez mais restritivas à importação de bens de equipamento e aos contratos de transferência de tecnologia entre matriz e filial, ${ }^{16}$ de outro lado, novas formas de evasão de divisas foram colocadas em prática pelas firmas multinacionais. Com efeito, ccorreu um aumento significativo da participação dos serviços de supervisão de montagem nas contas externas do país. A possibilidade de pagamento destes serviços engendrou despesas com tecnologia estrangeira na ordem de 2 a $3 \%$ do total cios investimentos efetuados na indústria cimenteira entre 1972-1980(CNPq, 1982, p.57-68).

A forma pela qual as despesas de importação de tecnologia se processavam, levou o Estado a estabelecer uma regulamentação dos fluxos tecnológicos com o exterior. O capitai externo na forma de investimento direto - visando compor a Secção I da economia - foi, mais uma vez, a fónmula encontrada para fazer face às insuficiências tecnológicas ou mesmo financeiras. Em decorrência, as firmas

15 Pesquisa pessoal realizada junto ao INPI.

16 A legislação brasileira não permite o envio se royalties da fítial para a matriz. 
multinacionais que detinham a tecnologia de processo de cimento instalaram-se no interior do país como produtoras de bens de equipamentos.

A importação de tecnologia, incorporada aos homens ou alienada, foi a partir de então estimulada - no limite do cspaço da firma, circulando no seu interior - em detrimento da importação pura e simples da tecnologia incorporada aos bens de equipamento.

Algumas medidas restritivas foram impostas aos contratos de tecnologia entre matriz e filial à medida que o desequilíbrio das contas externas agravava-se. Este fato tornou"se evidente à partir de 1979 com o segundo choque do petróleo.

No nosso entender, o objetivo de tais restrições estava, antes de tudo, ligado à situação financeira do país e à necessidade de reduzir as despesas com divisas referentes à tecnologia. Isto fica evidente quando se observa que o Estado não jogou um papel decisivo no sentido de promover o desenvolvimento da capacidade de engenharia de concepção de projeto fora do controle das firmas multinacionais.

Em 1977, o Conselho Nacional de Desenvolvimento Industrial (CDI) exigiu da firma F. L. Smidth a assinatura do "Termode Responsabilidade" através doqual a empresa estaria engajada a não fazer algum pagamento em troca da tecnologia adquirida cie sua matriz dinamarquesa, exceção feita aos serviços de supervisão de montagem de equipamentos nas usinas de cimento. Esta política foi estendida à Polysius. A possibilidade de enviar divisas por esta via estimulou outros contratos do mesmo gênero os quais foram todos averbados pelo INPI. O principal argumento da F. L. Smidth "era que a mesma não tinha interesse em fazer a supervisão de montagem no país, já que a sua matriz centralizava esses serviços na Dinamarca. Outro argumento era que isso seria condição básica para a garantia do desempenho dos equipamentos a seus clientes"(INPI, 1980, p.2).

Por seu lado, o INPI, em 15/08/1980, obedecendo a decisão de 1977 do CDI, deixou de permitir o estabelecimento de contratos de supervisão de montagem com o exterior. No máximo seria admitido um "adviser" a fim de dar garantia à tecnologia ofertada aos clientes. $O$ argumento baseava-se no fato de que os equipamentos eram produzidos no páis, assim como a engenharia de base i de detalhe. A empresa não tinha, pois, direito de exigir garantias na supervisão de montagem(INPI, 1980, p.2).

Observando os dois maiores fornecedores de equipamentos, verificamos que, a partir do ano de 1980, o númeto de contratos de supervisão de montagem não averbados pelo INPI é crescente. A autorização de contratos dessa natureza foi concedida, sobretudo, aos contratos apresentados antes da resolução de 1980 ou àqueles que estavam nas regiões prioritárias: Norte e Nordeste. ${ }^{17}$ Aliás, a partir de 1979, a isenção de tarifas alfandegárias sobre a importação de bens de equipamento sem equivalente nacional só foi concedida a projetos localizados nessas regiões.

17 Pesquisa pessoal realizada junto ao INPI. 
A partir da prática dessas políticas do INPI, o Governo brasileiro coloca em evidência que a importação de tecnologia, tal qual vinha se processando, pode se constituir num fator de bloqueio para o desenvolvimento de uma infra-estrutura científica e técnica nacional, na medida eñ que a pesquisa básica é concentrada na matriz. As firmas multinacionais não têm interesse em desenvolver a capacidade de engenharia local e de construção de bens de equipamento, isto é, não há interesse dessas firmas em estimular as verdadeiras operações de transferência de tecnologia.

Podemos citar, a título de exemplo, algumas restrições impostas pelo INPI aos contratos tecnologicos entre matriz e filiais de firmas multinacionais. ${ }^{18}$ Assim temos:

a) os quatros contratos ( 3 de montagem e 1 de assistência técnica) apresentados, entre 1979 e 1980, ao INPI pela "Indústria Pesada F. L. Smidth", tendo como cedente sua matriz, foram negados ou arquivados;

b) o contrato apresentado, em 1973, visando a uma licença de exploração de patente pela "Allis Chalmers S/A", tendo como cedente sua matriz americana, foi arquivado;

c) o contratu de assistência técnica apresentado pela "Krupp Indústrias Mecânicas", em 1979, tendo como cedente Fried Kurpp GMBH, assim como o contrato de cooperação técnico-industrial entre elas, em 1985, foram recusados.

Contrariamente, um só contrato foi recusado no conjunto dos 51 contratos de toda sorte apresentados pela firma Jaguará S/A com relação a seus cedentes estrangeiros, entre 1972 e 1985, compreendendo a tecnologia de fabricação de equipamentos para cimenteiras através de licença de firma inglesa.

O diagnóstico do III Plano Brasileiro de Desenvolvimento Científico e Tecnológico (PBDCT), em 1982, nos dá conta de que para o setor cimenteiro "a transferência de tecnologia não se processou em nível desejado. O fornecedor de engenharia de deialhamento e especificação para a construção de equipamentos não repassa os dados básicos que permitiriam uma maior absorção de know-how e, assim, os produtores ficaram habilitados à operação éficiente das unidades industriais e os fabricantes de equipamentos condicionados ao uso de tecnologia externamente(CNPq, 1982, p.58).

O mesmo documento assinala os fatores de inibição do desenvolvimento tecnológico do setor:

- concentração da engenharia de fabricação de bens de equipamento em filiais estrangeiras situadas no país, sem absorção, adaptação ou inovação importantes pelos institutos de pesquisa ou empresas nacionais;

- ausência no interior do país de capacidade e infra-estrutura de pesquisa em engenharia de processo;

18 Pesquisa pessoal reatizada junto ao INPI. 
- falta de recursos humanos ligados às atividades técnicas de laboratório e operacionais.

A partir deste diagnóstico, algumas medidas foram propostas a fim de promover uma certa capacidade tecnológica nacional. Contudo, estudos e pesquisas realizados, tendo em vista o Congresso da Indústria Cimenteira de 1986, colocavam em evidência, mais uma vez, a necessidade da implantação de um centro de estudos em engenharia de processo. ${ }^{19}$

A realidade dos anos 80 nos dá conta de que os empresários da indústria cimenteira brasileira tiveram que recorrer ao exterior para resolver problemas complexos de manutenção nas suas instalações, apesar dos equipamentos serem produzidos internamente, o que demonstra que a concepção básica dos projetos industriais é cfetuada no exterior.

É interessante ressaltar que organismos oficiais como o CDI ou entidades de classe como a Associação Brasileira para o Desenvolvimento da Indústria de Base(ABDIB) admitem um índice de nacionalização dos equipamentos para a indústria cimenteira de $99 \%$ sob pretex to de que todos os bens de equipamento são produzidos localmente à exceção dos equipamentos eletrônicos de comando e de laboratório. ${ }^{20}$

Ora, o índice de nacionalização, além de apresentar sérias dificuldades de cálculo devidas à declaração dos equipamentos, refere-se àquiloque foi importado em termos concretos de bens de equipamento. ${ }^{21}$ De fato, este índice não é muito significativo quando se observa a origem da tecnologia e seu grau de apropriação pelas empresas nacionais. Sem dúvida, a grande maioria dos equipamentos pode ser produzida localmente, todavia a dependência das filiais, no que se refere ao projeto básico, nos dá conta de uma situação inversa àquela descrita pelos organismos citados, CDI e ABDIB. Na realidade, desde os estudos básicos sobre matérias-primas são efetuados no exterior. Segundo um ex-técnico do Instituto de Pesquisas Tecnológicas de São Paulo(IPT), que esteve ligado diretamente à pesquisa de domínio do processo de fabricação de cimento, no Brasil se faz apenas soldagem de chapas, a pesquisa básica não existe mesmo para o que se refere ao conhecimento das transformações fisico-químicas que se passam no processo produtivo.

19 Houve, pelo menos, duas tentativas de pesquisa sobre a engenharia de processo no caso do cimento, ambas na segunda metade da década de 70 O primeiro contrato givbal de transferência de tecnologia, o governo brasileiro. atraves do INPI, assinou com a Prospective Enginneering Gestion, empresa suiça 0 segundo, o Instituto de Pesquisas Tecnologicas de São Paulo (IPT) tentou um intercâmbio com a Japan International Cooṕration Agence(JICA), através do CNPq visando à instálação de uma usina piloto e o desenvolvimento de metodologia para efetuar estudos das matérias-primas. $O$ IPT levou dois anos para convencer os fabricantes de cimento e de equipamentos a apoiar este projeto a fim de que o governo assinasse o acordo. Este contrato, que deveria ser estabelecido entre governos - Brasil e Japão - foi arquivado.

20 Entrevistas realizadas na ABIDIB com técnicos encarregados de pesquisa na área de tecnologia de processo e com integrantes do grupo técnico da área de cimento do CDI.

21 Sobre as dificuldades de cálculo do índice de nacionalizaçăo ver particularmente Campos (1976). 
A dependência tecnológica da indústria cimenteira brasileira seguiu uma trajetória bastante corrente na medida em que se trata de um aparelho produtivo implantado num contexto de industrialização tardia. Inicialmente, a importação de equipamentos e de serviços técnicos quase sempre recorrendo a contratos "clef en main" constitui a forma dominante da dependência. Posteriormente, a natureza da dependência é deslocada para os serviços de engenharia de projeto e de assistência técnica - tecnologias desincorporadas * as quais constituem efetivamente o núcleo central da dependência.

De um lado, a transferência do saber técnico que permite o domínio da engenharia de projeto dos equipamentos para a indústria cimenteira não ocorreu (núcleo central para o controle da tecnologia), de outro lado, constata-se a transmissão do saber que permite o controle nạ condução dos meios técnicos utilizados nas unidades de produção de cimento.

O rendimento obtido das instalaçc̃es constitui, de uma maneira ou de outra, expressão imediata do domínio na condução dos meios técnicos importados no momento da produção. É preciso assinalar que não podemos generaliz? as experiências, visto que vários elementos influenciam no resultado da assimilação tecnológica. ${ }^{22}$

Os produtores de cimento estão"satisfeitos com a tecnologia utilizada e asseguram uma produção compativel com o mercado interno. As firmas multinacionais chamadas para fornecer equipamentos à indústria de cimento o fazem de maneira satisfatória. Neste contexto, marcado pela convergência de interesses dessas duas frações do capital, o Estado desempenha um papel deliberadamente passivo no que se refere à política científico-tecnológica que possa promover a autonomia tecnológica nacional nesta área. Sem dúvida, o papel do Estado como organizador da promoção da capacidade local de engenharia e de concepção de bens de equipamento é crucial para o estabelecimento de uma infraestrutura tecnológica.

\section{CONSIDERAÇÕES FINAIS}

Até os anos 76, o meio utilizado no Brasil por aqueles que se lançaram na fabricação de cimento foi a importação de tecnologia incorporada aos equipamentos e necessária à sua utilização.

Em nível mundial, a concentração da produção de tecnologia para obter cimento erì algumas firmas conduz a uma tendência de homogeneização internacional das normas técnicas da produção, particularmente no que se refere ao núcleo estratégico da produção cimenteira - a transformação. Esta homogeneização orienta-se em direção a dois pontos-chave: a iniıgração do fluxo produtivo, influenciando diretamente nos rendimentos das instalações - suporte da economia

22 Os elementos sāo, entre outros: os equipamentos utilizados, a política patronal de gestão da força de trabalho, as especificidades śrcio-cconômicas locais 
de tempo - e o crescimento do tamanho da planta, favorecendo as economias de escala.

No que se refere ao processo de fabricação (via seca ou úmida), constata-se que a introdução de novos processos no Brasil acompanhou a evolução das normas de produção em nível mundial. É preciso assinalar que oritmo de difusão dos novos processosocorreu em sintonia comas características inerentes à indústria cimenteira. De fato, as grandes imobilizações de capital fixoe a alta incidência dos custos fixos na formação do valor de troca de seu produto orientavam a introdução do processo via seca no Brasil no momento em que havia necessidade de expandir acapacidade produtiva da indústria cimenteira.

Se, de um lado, a difusão de tecnologia do processo de fabricação de cimento nn Brasil ocorreu sem obstáculo ao longo dos anos, de outro a transferência de tecnologia reflete que a dominação da engenharia de projeto - núcleo estratégico da transferência de tecnologia - não ocorreu até o presente. A capacidade de engenharia nacional na área do processo de fabricação de cimento é muito fraca, eriquanto a grande maioria dos equipamentos é atualmente produzida no interior do país. Isto se explica pelo fato de que uma grande parte das firmas multinacionais, que detém a tecnologia de processo em nível mundial, instalaram-se no Brasil enquanto indústrias mecânicas desde os anos 70, tendo em conta as restrições impostas pelo governo à importação de bens de equipamento. Além disso, essas firmas fornecem projetos básicos a firmas nacionais licenciadas para a produção de equipamentos. Nos dois casos, a tecnologia de concepção dos equipamentos. Nos dois casos, a tecnologia de concepção dos equipamentos - a engenharia de projeto - continua residindo na matriz, no exterior. O que ocorre, na realidade, é a chamada "transferência internalizada". A capacidade de produção interna não corresponde necessariamente autonomia tecnológica.

A boa performance da indústria cimenteira brasileira - a relação entre capacidade de produção real e capacidade teórica demonstra que a transmissão do conhecimento técnico tornou possível a dominação na condução das instalações com conteúdo tecnológico importado.

Por fim, há que destacar o papel passivo desempenhado pelo Estads brasileiro na condução e promoção de uma políica científico-tecnológica capaz. de impulsionar a capacidade de engenharia nacional na área em questão.

\section{BIBLIOGRAFIA}

ANGEL.IER. J. P. Etude sur I'Evolution de la Concentration dans I'Industrie du Ciment en France Bruxelas: CEE, 1978. (Collectin Etudes, Série Évolution de la Concentration et de la Concurrence, $\mathrm{n}^{\circ} 13$ ).

ASSOCIAÇĀO BRASIL.EIRA DE MERCADO DE CAPITAIS. O Setor de Cimento no Brasil, Rio de Janeiro: ABRAMEC, 1981.

CAMPOS. M. A O Mito do Indice de Nacionalização. Rio de Janeiro: IPEA, 1976. 
CNPQ-III PABDCT. Açĩo Programada em Clência e Tecnolagla: Indástria de Produtos Intermedínrios não Metálicos, Cimento, Celulose e Papel. Brasilia: SEPLAN, 1982.

CORIAT, B. Ouvriers et Automates: Trois Etudes sur la Notion d'Industrie de Processus. Paris: CRESSTUniversite Paris Sud, 1980.

Transfert de Techniques. Division du Travail, Politique de Main-d'Oeuvre, Critiques de I'Economie Politique. Paris: Maspero, nova série, n. 14, jan/mar. 1981.

DADOY, M. Politique de Gestion de Personnel dans I'Industrie Cimentièn. In: Aspects Humains de I'Automatisation (Actes de la Journee). Paris: ACFET, 1978.

EMBRAMEC. Coletânea de Aspectos Tecnologicos do Setor de Bens de Capital. Rio de Janeiro: BNDES, 1979.

GUIMARÃES, E. \& REIS, L. O Processo Via Seca na Indústria de Cimento In: Difusão de Inovaçōes na Indústria Brasileira: Três Estudos de Caso. Rio de Janeiro: IPEA, 1976. (Série Monografica, $\left.n^{\circledR} 24\right)$.

FGV. Política Industrial e Exportaçâo de Manufaturados do Brasil. Rio de Janeiro: FGV, 1983.

INPI. Ato Normativo n 015 de 11 de setembro de 1975. Revista da Propriedade f́ndustrial. Rio de Janeiro: INPI, 1975

Contratos de Supervisão de Montagem de Equipamentos - Setor Cimento Revista de Propriedade Industrial. Rio de Janeiro: INPI, n 5, abr, 1980.

LAFARGEConsultoria e Estudos. Perspectivas da Indústria Cimenteira na Presente Década. Brasília:MIC/CDI, 1982.

LUTRIN, A. Historique de l'Automatisation en Cimenterie. In: Aspects Humains de I'Automatisation (Actes de la Journee), Paris: ACFET, 1978.

MADEUF, B. L'Ordre Technologique Internacional Paris: La Documentation Française, N. D. 4641, 1981.

MELO. M. Cristina P. de. Procès de Production et Diffusion Internacionale de Technologie. Paris: Universidade de Paris, 1989, Thèse (dout. econ.).

PERRIN, J. Les Transferts de Technologie. Paris: Maspero, 1983.

\& JUDET, P. Problématique Economique. In: Transfert de Technologie et Dévélopment. Paris: Librairies Techniques, 1977.

PROCHINIK, V. A Dinâmica da Indústria de Cimento no Brasil Rio de Janeiro: Universidade Federal do Rio de Janeiro, 1983. Dissert (mestr. econ.).

\section{ABSTRACT \\ DIFFUSION AND TRANSFER OF CEMENT PRODUCTION TECUNOLOGY IN BRAZIL}

This article analyses the process of international diffusion and transfer of cement production technology in Brazil It examines the evolution of cement production in terms of world standands, emphasizing the principle of technological changes. The speed of introducing new process of production in Brazil has been considered Finally, this article analyses the industry of equipment goods for the Brazilian cement sector, aiming to identifying the level of technological appropriation ocurrence. 